\title{
Group playing by Ear in Higher Education: the processes that support imitation, invention and group improvisation
}

In our rapidly changing cultural world many musicians will choose to follow a 'portfolio career' (Bennet, 2016; Hallam \& Gaunt, 2012) and will be called upon to respond to new types of professional demands by demonstrating their creative and improvisation skills; their knowledge of stylistic diversity, repertoire and performance practices across different musical genres; and their collaborative skills and facility with different instruments and voice.

Being creative is a core quality of the twenty-first century musicians along with collaborative enquiry, risk-taking, flexibility and autonomy (Bennet, 2016; Guillaumier, 2016). The term 'creativity', however, similarly to 'improvisation', often creates anxiety amongst music learners of the western classical tradition. Probably, this is because the term is elusive, commonly perceived by music students as magical and mystical, qualities that they either possess or not. Western classical musicians might even feel that the so-called 'vernacular' (i.e. traditional folk, jazz, pop, world) musicians are indeed creative, for unlike them, they improvise and 'make up' 'their own' music during group musical interactions.

The study presented here explored how group playing by ear, or Group Ear Playing (GEP), through the imitation of recorded material and opportunities for inventive work during peer interaction supported first year undergraduate western classical music students' aural, creative and improvisation skills. The approach to playing by ear adopted in this study is based on Lucy Green's (2014) work on the use of informal learning practices in formal music education. The framework that emerged from the analysis of the data describes two routes taken by the students, whilst progressing from GEP to group improvisation. This study advocates that through playing by ear in groups western classical musicians within Higher Education can develop their creative, collaborative and improvisation skills. 


\section{Playing by ear and creative music education}

Playing by Ear has been defined as the process of playing music 'without the aid of notation, without the visual stimulus of watching a live instrumental model, without verbal hints such as solfege' (Musco, 2010, p. 49) and through playing back from recordings (Green, 2012; Varvarigou, 2014; Varvarigou \& Green, 2015). Playing by ear in a group (GEP) describes the process of learning, within a group, through playing back from recordings, but it does not exclude the imitation of a model - seen and heard, as in the case of imitating peers' practice, technique or interpretation.

Unlike traditional folk, jazz, pop, rock and 'world' musicians who regularly engage in playing by ear from recordings as a means of learning new repertoire and of creating new material either as improvisations or as compositions (Berliner, 1994; Green, 2002; Nettl \& Russell, 1998) the training of western classical musicians does not usually include playing by ear as an equally valued and regular component of their training and practice. Ironically, playing by ear has been indentified as supporting the development of performing rehearsed music, playing from memory, sight reading and improvisation (McPherson, Bailey, \& Sinclair, 1997). These skills feature prominently in the training of western classical musicians (Williamon, 2004). For instance, having the ability to 'adapt constantly to changing [musical] environments' (Thompson \& Lehmann, 2004, p. 143) during improvisation and sight-reading, as well as responding to 'moment-by-moment novelty...[by] accommodating a co-performer's sudden change of tempo or coping with a memory slip' (Davidson \& King, 2004, p. 105) during ensemble practice are musical skills that feature high on the agenda of HE institutions that prepare graduates for the music profession. Engaging in playing by ear activities allows the musicians not only to develop their aural and creative abilities to imitate sounds, but also to adapt and respond to changes in these sounds. These changes could be a result of a coperformer's musical interpretation, memory slip, or a response to an improvised phrase.

Burnard (2012, p. 333) advocates that in music education we need to foster practices 
that directly reinforce creativity. These practices 'need to promote the power relationships over individual minds, multiple worlds over singular realities, collaborative interdependence over individual heroism, and dialogue over alienation'. In addition, according to Sawyer (2007, p. ix) 'collaboration is the secret to breakthrough creativity'. Other scholars also recognize that creativity prospers best within environments that encourage exchange of ideas amongst people with different levels and kinds of expertise as well as environments that foster risk-taking and experimentation (Gibson, 2010; Grainger, Barnes, \& Scoffham, 2004). In other words, the ideal conditions for creativity can be experienced in groups, during interactions characterised by playful experimentation. Finally, it has also been maintained that affective involvement of the group members is central to creativity, for it facilitates the creation of a safe environment where the group members can take risks and operate out of their comfort zones.

\section{GEP with undergraduate western classical musicians}

Forty-six first year undergraduate students took part in a 5-week GEP segment of a HE Practical Musicianship module. The programme aimed at developing the students' aural, creative musicianship and improvisation skills by encouraging them to play musical pieces from different musical genres (popular, classical and a piece of free choice) by ear in small groups of five to seven musicians. The term 'improvisation' is used here to describe the performance of music which is not written down, and which encompasses both variations in the interpretation of given musical material and the creation of new musical material that has been produced through creative decision making 'within the real time of the performance' (Hallam \& Gaunt, 2012,pp. 97-98). The student cohort was divided into 8 groups. Each group engaged in GEP for approximately forty minutes every week. There was no tutor present during the GEP sessions. 
The students were asked to create freer renditions rather than accurate imitations of the original pieces copied. Moreover, they were encouraged to experiment with the musical material by making changes in the dynamics, tempo, rhythm, harmony and even the melody, and to create and add new material to the pieces copied as long as they kept the flow of the music. The students played their principal or second instrument. Forty-three percent (20/46) reported no prior experience in GEP as opposed to 31\% (14/46) who reported having some experience and 26\% (12/46) who did not respond. Data were collected through students' individual Reflective Logs (RL) (n=194), end-of-programme Feedback Forms (FF) (n=36) and Interviews (I) $(n=4)$ (a detailed description of the programme can be found in Varvarigou, 2016; Varvarigou, forthcoming). Each student filled in a RL at the end of each session. The FF were collected at the end of the fifth session for each group and the interviews took place at the end of the academic year with four students (two males and two females). Three out of the four students selected received high marks for GEP but had reported in their FF that they had never engaged in playing by ear in a group before. The fourth student was selected because she indicated in her RL and FF that she found the programme 'out of her comfort zone' and non-enjoyable. All interviews were audio-recorded and transcribed verbatim for analysis. The audio material used for the first two stages of this GEP programme is available in the book 'Hear, Listen, Play' (Green, 2014). The analysis of the data focused on thematic discovery from the transcripts and was achieved through open, axial and selective coding (Creswell, 2007).

\section{Moving from Group Playing by Ear to Improvisation}

The analysis of the data revealed two approaches to engaging in imitation, invention and improvisation. What is particularly interesting is that three of the eight groups of students who participated in the GEP programme used both routes whilst creatively experimenting with the pieces. The first was the cognitive approach, which was initially adopted by three groups (see Figure 1). After the members of these groups had learnt each part the musicians 
started improvising by altering the structure of the pieces - different riffs or melodic lines comprised the introduction, ending and improvisation sections. This was achieved through switching different melodic lines around. The second approach to engaging in imitation was the auditory approach, which was initially adopted by two groups. This involved listening to the recording and playing extensively along with the recording. Individual strategies for finding the first note included playing a scale or playing random notes until they found one of the notes of the riff, which they then used as an anchor to develop the riff. Some musicians focused on imitating the rhythm first, some imitated the pitch and rhythm simultaneously, and one sang a scale to find the first note. During the process of invention that led to improvisation the musicians in five out of the eight groups listened to the pieces and allocated the different parts according to what they thought was the appropriate instrument. They then started harmonising the melodies played by their colleagues. Imitation and invention also encompassed guessing. This enabled them to compensate for limitations in understanding harmonic or melodic relations in the music or for limitations of experience of playing by ear.

\section{Group imitation, invention and improvisation}

- 'I've learnt that with a small group of musicians doing a task like this you can produce good, fast results whilst having lots of fun' (Joshua, xylophone, FF)

- I most enjoyed putting all the parts together as a group and discussing how to change it' (Dylan, euphonium, FF)

Group improvisation was instigated by the group members to 'make the pieces sound more interesting' (Eva, flute, RL 1). Altering the pieces' structure was part of the groups' creative experimentation with the given material, which made the pieces their own. Likewise, the group members that followed the auditory route reportedly used improvisation in order not only to play together but also to complement each other. Both the 'cognitive' and the 
'auditory' routes enabled the groups to progress from purely imitating the musical phrases to inventing answering phrases, extemporising new phrases, improvising by embellishing the melodic lines to creating new melodic lines that were added as different sections to the pieces copied. Each group's final performance after five weeks of GEP comprised variations of the pieces copied that were created on the spot and 'new' sections that were pre-composed but embellished on the spot. This suggests that GEP not only allowed the classical musicians to engage in spontaneous improvisation but also to explore ways of composing their own sections to the music copied by ear.

Figure 1. From Group Ear Playing to Group Improvisation

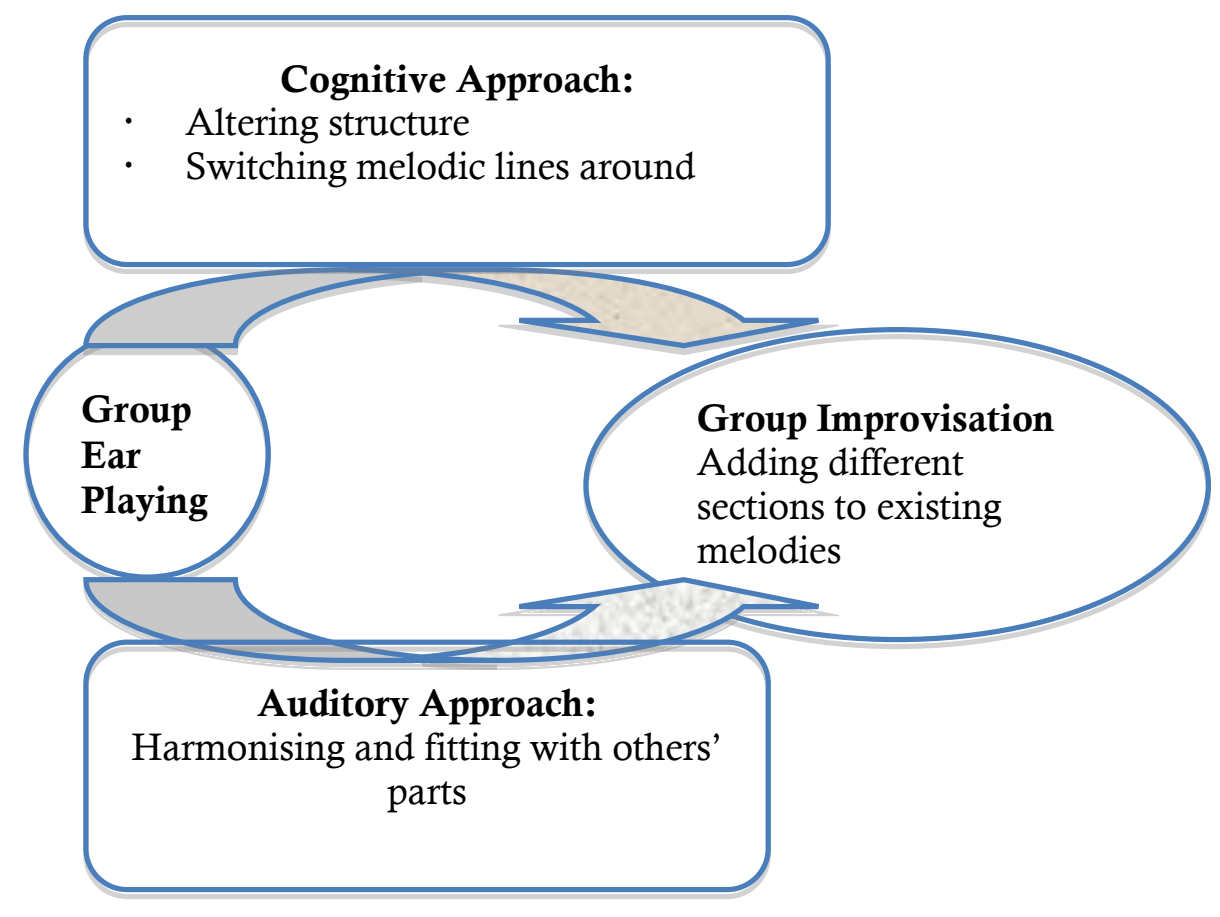

\section{The challenges of group imitation and invention}

The challenges articulated by the musicians included hesitation to move out of one's comfort zone; not having written notation and having to play on a second study instrument, made some participants find playing by ear in a group particularly tricky. Other challenges expressed by the students were related to the repertoire copied. For example, the classical 
pieces were considered difficult to copy by ear because they had complex harmony; the extracts were longer and therefore difficult to remember as opposed to the shorter riffs of the popular music track. Some students talked about feeling uncomfortable playing and improvising in front of others. Others talked about the challenges of getting the group to focus, of working in mixed ability groups and of arranging the pieces for the instruments available. Nonetheless, although copying musical repertoire by ear in small groups posed several challenges for the classical musicians, it allowed them to develop their aural skills whilst imitating musical pieces, and whilst arranging them by altering their harmonies and musical structures. Furthermore, through GEP the musicians engaged in improvisation and the invention of new material through collaborative group processes that legitimated individual creativity and that nurtured group creativity (Hallam \& Gaunt, 2012). This was facilitated by peer support and playful experimentation and by repertoire in a variety of musical genres.

\section{Playing by Ear in $21^{\text {st }}$ century HE: nurturing creative practice}

The successful career musicians in the twenty-first century need to be musically versatile, creative and flexible, ready to problem-solve and to take risks within collaborative partnership. These skills can flourish as a result of collective experimentation and interaction within a music group (Johnston, 2013; Nettl \& Russell, 1998). Musical skills such as improvising, arranging and musical leadership can be ideally nurtured through collaborative learning and group interactions, for musicians are free to collectively experiment together and to develop personal musical responses to their specific social and cultural situations. For Johnston (2013, p. 392) a properly presented improvisation pedagogy rooted in collective experimentation is likely to support individuals to 'make important personal creative breakthroughs' and to 'nurture in students a disposition that recognises that our situations both musical and social - are mutable rather than fixed'. 
Within a HE context, exploring how western classical musicians could develop their listening, improvisatory and creative musicianship skills through playing by ear - an approach used extensively by vernacular (i.e. traditional folk, jazz, pop, world) musicians - is an area that has recently received noteworthy attention (Ilomäki, 2013; Prchal, 2013). The study presented here placed emphasis upon playing by ear in a group, for group playing has been found to enhance listening and technical skills, motivate learners to practise with direct links to increased achievement (Hallam \& Kokotsaki, 2007), create a sense of belonging and of making an active contribution to a group, support the creation of friendships and to boost the participants' social skills (Hallam \& Gaunt, 2012). Playing in groups also supports teamwork skills, self-discipline and concentration, a sense of responsibility towards shared goals and purpose of the group.

\section{GEP and Chinese Higher Education}

Higher Education in China promotes excellence in Western Classical and Chinese Classical traditions (Yang, 2016), and more recently in popular music (Musical Futures, 2016). Musicians in these different musical traditions in China and around the world achieve excellence by adopting musical practices and processes that are perceived to be 'authentic' to the musical traditions they come from. For example, traditional/folk musics are aligned with the master-apprentice model of teaching and learning (Nettl \& Russell, 1998; Yang, 2016), which is notably resistant to facilitating the learners' playful experimentation with the musical material and the learners' creative imitations, inventions and improvisations of this material as part of their learning process.

On the one hand, I strongly believe that musical traditions should be preserved and respected, for different musics reflect different applications of musical roles, values, ways of learning and ways of teaching. On the other hand, I feel that by shifting the focus from the musical material onto the skills developed through encountering this material, especially 
when interacting with others in the process of learning it, music learners gain a deeper understanding within Higher Education of the processes of musical teaching and learning, a greater appreciation of the music, a greater awareness of the collaborative and social perspective of music making and develop creativity. In western classical art music tuition with Higher Education in Europe and North America there appears to be a growing recognition for the inclusion of imitation, invention and improvisation as part of the musicians' education and practice as a way of supporting different musical creativities (Burnard, 2012).

Too much detail limits creativity but without a framework creative ideas can be generated with difficulty. Playing by ear activities for western classical musicians in HE could start with material that is organised in separate riffs and melodies that allow the musicians who are unfamiliar with the process of aural learning to create a bridge between cognitive strategies, which are influenced by their knowledge of theory and musical analysis; to auditory strategies that could lead to more spontaneous responses to music making. In the study presented here playing by ear in groups has reportedly helped music students most of whom were pursuing a trajectory towards professional careers in music to develop aural, creative and improvisation skills. These skills have been identified as essential in 'just about any career in music' (Hallam \& Gaunt, 2012, p. 178).

I therefore advocate for playing by ear in groups to be a core part of music curricula in HE not least because it nurtures the development of the musical skills of imitation, invention and improvisation that could be used by all musicians in preparation for successful portfolio careers in performance, teaching and artistic leadership in different contexts (Smilde, 2009). What is more, social interaction is part of the skill of being a musician; playing by ear within a group seems to have contributed to the development of individual aural skills but also to have enabled groups with diverse skills to learn how to work together. 


\section{References}

Bennet, D. (2016). Developing employability in higher education. Arts \& Humanities in Higher education, 15(3-4), 386-413.

Berliner, P. (1994). Thinking in jazz: The infinite art of improvisation. Chicago: Univerity of Chicago Press.

Burnard, P. (2012). Commentary: Musical Creativity as practice. In G. McPherson \& G. Welch (Eds.), The Oxford Handbook of Music Education (Vol. 2, pp. 319-336). Oxford: Oxford University Press.

Creswell, J. (2007). Qualitative Inquiry \& research Design - Choosing among five approaches (Second ed.). Thousand Oaks: Sage Publications.

Davidson, J., \& King, E. (2004). Strategies for ensemble practice. In A. Williamon (Ed.), Musical Excellence -Strategies and techniques to enhance performance (pp. 105-122). Oxford: Oxford University Press.

Gibson, R. (2010). The 'art' of creative teaching: implications for higher education. Teaching in Higher Education, 15(5), 607-613.

Grainger, T., Barnes, J., \& Scoffham, S. (2004). A creative cocktail: creative teaching in initial teacher education. Journal of Education for Teaching, 30(3), 243-253.

Green, L. (2002). How popular musicians learn. Aldershot: Ashgate Publishers.

Green, L. (2012). Musical 'learning styles' and 'learning strategies' in the instrumental lesson: Some emergent findings from a pilot study. Psychology of Music, 40(1), 42-65. doi:10.1177/035735610385510

Green, L. (2014). Hear, Listen, Play! How to free your students' aural, improvisation and performance abilities. Oxford: Oxford University Press.

Guillaumier, C. (2016). Reflection as creative process: Perspectives, challenges and practice. Arts \& Humanities in Higher education, 15(3-4), 353-363.

Hallam, S., \& Gaunt, H. (2012). Preparing for success - a practical guide for young musicians. London: Institute of Education.

Ilomäki, L. (2013). Learning from one another's musicianship: exploring the potential for collaborative development of aural skills with pianists. In H. Gaunt \& H. Westerlund (Eds.), Collaborative learning in Higher Music Education (pp. 123-133). Surrey: Ashgate.

Johnston, P. (2013). Teaching improvisation and the pedagogical history of the Jimmy Giuffre 3. International Journal of Music Education, 31(4), 383-393.

McPherson, G., Bailey, M., \& Sinclair, K. (1997). Path analysis of a theoretical model to describe the relationship among five types of musical performance. Journal of research in music education, 45(1), 103-129.

Musco, A. M. (2010). Playing by Ear: Is Expert Opinion Supported by Research? Bulletin of the Council for Research in Music Education, 184, 49-63.

Musical Futures. (2016). Network with teachers from Cambodia, Singapore, Malaysia, Thailand, Vietnam, Hong Kong, China, Australia and the UK. Retrieved from www.musicalfutures.org

Nettl, B., \& Russell, M. (Eds.). (1998). In the course of performance - Studies in the world of musical improvisation. Chicago: The University of Chicago Press.

Prchal, M. (2013). Report of the ERASMUS Intensive Programme Improvisation in European Higher Music Education: Improving Artistic Development and Professional Integration (Grant Agreement Number ERA/IP/13/45). Retrieved from The Hague:

Sawyer, K. (2007). Group Genius - The creative power of collaboration. New York: Basic Books. Smilde, R. (2009). Musicians as lifelong learners - Discovery through biography. Dreft: Eburon Academic Publishers.

Thompson, S., \& Lehmann, A. (2004). Strategies for sight-reading and improvising music. In A. Williamon (Ed.), Musical Excellence - Strategies and techniques to enhance performance (pp. 143-159). Oxford: Oxford University Press. 
Varvarigou, M. (2014). Play it by ear: teachers' responses to ear-playing tasks during one to one instrumental lessons. Music Education Research, 16(4), 471-484.

Varvarigou, M. (2016). Collaborative playful experimentation in Higher Education: A Group Playing by ear study. Arts \& Humanities in Higher education, 15(3-4).

Varvarigou, M. (forthcoming). Promoting collaborative playful experimentation through group playing by ear in Higher Education. Research studies in Music Education.

Varvarigou, M., \& Green, L. (2015). Musical ,Äòlearning styles, Äô and ,Äòlearning strategies,Äô in the instrumental lesson: main-study findings. Psychology of Music, 43(5), 705-722.

Williamon, A. (2004). Musical Excellence; Strategies and techniques to enhance performance. Oxford: Oxford University Press.

Yang, Y. (2016). Music Performance in a 'Transitional Era' of education: A Case study of folk song performance in China. In I. Papageorgi \& G. F. Welch (Eds.), Advanced Musical Performance: Investigations in Higher Education learning (pp. 77-95). Oxon: Ashgate

This short paper is based on an extended research paper submitted to the British Journal of Music Education in March 2016. 